\title{
New Tropospheric OH Measurements
}

\author{
U. Platt, M. Rateike, ${ }^{1}$ W. Junkermann, ${ }^{2}$ J. Rudolph, and D. H. Ehhalt \\ Institut für Chemie der Kernforschungsanlage Jülich GmbH, Jülich, Federal Republic of Germany
}

\begin{abstract}
New field measurements of atmospheric $\mathrm{OH}$ radicals by laser long-path absorption spectroscopy are reported: In the Black Forest, diurnal profiles of $\mathrm{OH}$ radical concentrations ranging up to $8.7 \times 10^{6}$ $\mathrm{cm}^{-3}$ have been observed during June 1984. Simultaneous measurements of other trace gases, photolysis frequencies, and meteorologic parameters were also made to allow comparison of observed $\mathrm{OH}$ levels with model calculations.
\end{abstract}

\section{INTRODUCTION}

Hydroxyl radicals play a central role in the chemical cycles of most atmospheric trace gases. Since the introduction of this idea by Weinstock [1969] and Levy [1971], a comprehensive and relatively consistent theory has been developed concerning the radical's sources, chemical cycles, and sinks in the trophosphere (see, for instance, Crutzen [1973]; Fishman and Crutzen [1977]; Logan et al. [1981]).

In contrast to the well-developed theory, the state of its experimental verification is less than satisfactory. Although a number of atmospheric $\mathrm{OH}$ measurements have been published (for an overview, see Hübler et al. [1984]), most of those are explorative in nature, primarily aimed at demonstrating the performance of the $\mathrm{OH}$ detection technique. While it is clearly necessary to demonstrate that a given technique is sufficiently sensitive and specific, the ultimate goal in measuring atmospheric $\mathrm{OH}$ radical concentrations is to provide a test of the photochemical theory.

In order to allow comparison of measured $\mathrm{OH}$ concentration levels with theoretical predictions in a meaningful way, the air mass in which $\mathrm{OH}$ is measured must be chemically characterized. Thus it is essential to measure a number of supporting parameters simultaneously with the $\mathrm{OH}$ concentration. As discussed in detail by Perner et al. [1987], those parameters include the solar UV flux, humidity, and the concentrations of a number of trace gases, such as $\mathrm{O}_{3}, \mathrm{NO}_{2}$, $\mathrm{CH}_{2} \mathrm{O}, \mathrm{CO}$, and hydrocarbons. From the experimental side this requires a considerable effort in addition to the actual $\mathrm{OH}$ measurement.

Earlier field measurements by this laboratory [Perner et al., 1987] for the first time obtained a sufficiently complete set of supporting data to allow comparison of measured $\mathrm{OH}$ concentrations with predictions of photochemical reaction models. Surprisingly, in most cases the calculated $\mathrm{OH}$ levels were higher than actually observed levels. This overestimation of $\mathrm{OH}$ by the model appeared to be more significant at low $\mathrm{NO}_{x}$ mixing ratios. Since the measurements were made at moderately to highly polluted sites (Deuselbach, Jülich, in

${ }^{1}$ Now at Bayer Aktiengesellschaft, Leverkusen, Federal Republic of Germany.

${ }^{2}$ Now at Fraunhofer Institut fur Atmospharische Umweltforschung, Garmisch-Partenkirchen, Federal Republic of Germany.

Copyright 1988 by the American Geophysical Union.

Paper number 8D0073.

0148-0227/88/008D-0073\$05.00 the Federal Republic of Germany) only very few observations showed $\mathrm{NO}_{x}$ levels below $1 \mathrm{ppb}$.

Therefore new measurements were performed at a lesspolluted site in the German Black Forest during June of 1984 , which yielded a larger number of observations at $\mathrm{NO}_{x}$ levels below $1 \mathrm{ppb}$. In this paper we describe the experimental part of this campaign and present measured values of the $\mathrm{OH}$ concentrations as well as of the supporting parameters. Model calculations based on those data and comparison of model-calculated $\mathrm{OH}$ with the measured $\mathrm{OH}$ concentrations will be presented in a second publication.

\section{EXPERIMENTAL TECHNIQUe}

\section{The $\mathrm{OH}$ Experiment}

The long-path absorption spectroscopy (LPA) measurements of $\mathrm{OH}$ utilized the strong, narrow, and well-resolved rotational lines around $308 \mathrm{~nm}$. The $\mathrm{OH}$ lines $Q_{1}(2)$ and $Q_{21}(2)$ of the $A^{2} \Sigma^{+}, \nu^{\prime}=0 \leftarrow X^{2} \Pi^{3 / 2}, \nu^{\prime \prime}=0$ transition were selected for the detection of $\mathrm{OH}$.

The experimental setup has been described earlier [Hübler et al., 1984; Perner et al., 1987], thus only a general outline will be given in the following discussion. A laser system, consisting of a frequency-doubled dye laser synchroneously pumped by a mode-locked $(246 \mathrm{MHz}) \mathrm{Ar}^{+}$laser, served as light source. The width of the frequency-doubled laser emission profile was $\simeq 0.1 \mathrm{~nm}$ (full width at half maximum (FWHM)); the average UV output power ranged from 10 to $20 \mathrm{~mW}$. The laser light beam was expanded to about $25-\mathrm{cm}$ diameter, was passed through the free atmosphere, and was reflected back to the laser site; thus the total length of the light path was $8.6 \mathrm{~km}$ during all $\mathrm{OH}$ measurements. The received light was dispersed by a spectrograph installed next to the laser system, and a preselected portion $(\simeq 0.05 \mathrm{~nm}$ wide) of the spectrum around the $\mathrm{OH}$ lines was monitored through repetitive $(6.6-\mathrm{kHz}$ repetition rate) scanning and integration by a fast signal averager. The total integration time for a single measurement was of the order of 1 hour. Thus a final spectrum represented an average over some 20-30 million individual scans across the $0.05-\mathrm{nm}$ interval around the selected $\mathrm{OH}$ absorption lines.

Concentrations of hydroxyl radicals were determined from their differential optical absorptions according to Lambert-Beer's law. The only external parameter required to convert measured absorptions into concentrations is the absorption cross section of $\mathrm{OH}$, which can be readily obtained from literature data. Here an oscillator strength of $f=$ $7.3 \times 10^{-4}$ was derived from the Einstein coefficients calculated by Goldman and Gillis [1981], which are based on 


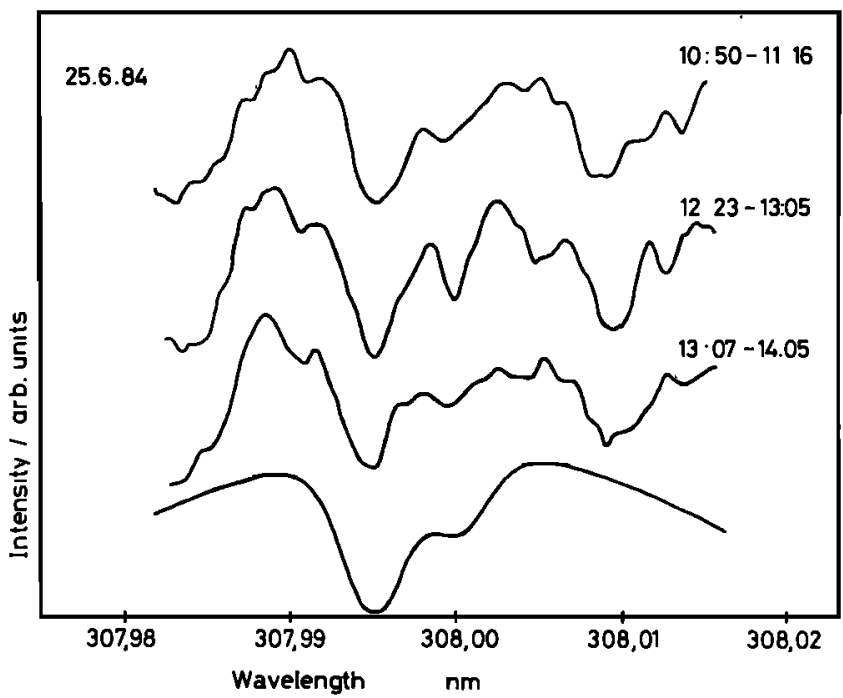

Fig. 1. Absorption spectra of the $\mathrm{OH}$ radical around $308 \mathrm{~nm}$. The $Q_{1}(2)$ and $Q_{21}(2)$ lines of the $A^{2} \Sigma^{+}, \nu^{\prime}=0 \leftarrow X^{2} \Pi, \nu^{\prime \prime}=0$ transition are clearly visible. In the flame spectrum (lowest trace) used as wavelength reference as a result of the higher temperature, the lines are broadened compared to the atmospheric spectra. The spectra were taken in the Black Forest, June 25, 1984, using 8.6-km light path length.

the lifetime measurements by German [1975]. Assuming Gaussian line shape, as discussed by Hübler et al. [1984], and taking the population of the ground state $\left(n / n_{0}=0.1\right)$ into account, an effective absorption cross section at line center of the $Q_{1}(2)$ line of $\sigma=1.5 \times 10^{-16} \mathrm{~cm}^{2}$ is obtained at a typical resolution of $\Delta \nu=0.4 \mathrm{~cm}^{-1}(0.0038 \mathrm{~nm})$.

The uncertainties in the $\mathrm{OH}$ concentrations thus determined from the measured spectra are mostly due to amplitude noise in the spectra. The principal source of amplitude noise is photon statistics; however, in several spectra unknown absorption lines occured. In order to account for the possibility that those features might occur at the spectral position of the $\mathrm{OH}$ lines, the rms noise of the baseline was calculated treating those unassigned absorption features as additional noise [Perner et al., 1987].

Sample absorption spectra clearly showing two $\mathrm{OH}$ lines $\left(Q_{1}(2)\right.$ and $Q_{21}(2)$ lines of the $A^{2} \Sigma^{+}, \nu^{\prime}=0 \leftarrow X^{2} \Pi, \nu^{\prime \prime}=0$ transition) are presented in Figure 1. The lowest trace in Figure 1 gives an $\mathrm{OH}$ reference spectrum used as wavelength standard. It is obtained by passing the laser light through an acetylene/air flame. Because of the high temperature, the lines are broadened compared to the $\mathrm{OH}$ lines observed in the atmosphere. The unassigned absorption line at $308.01 \mathrm{~nm}$ was treated as additional "noise" of the baseline.

\section{The DOAS Experiment}

Simultaneously with the $\mathrm{OH}$ measurements, the concentrations of $\mathrm{NO}_{2}, \mathrm{O}_{3}, \mathrm{CH}_{2} \mathrm{O}$, and $\mathrm{SO}_{2}$ were monitored by a second LPA spectrometer. These molecules were detected by their characteristic vibrational band structures, again using differential optical absorption spectroscopy (DOAS). The instrument and the data evaluation procedures are described in detail by Platt and Perner, [1983, 1984]. Although both instruments employ the same basic principle, the DOAS spectrometer is much simpler. First, the species measured by DOAS are roughly 10,000 times more abundant than $\mathrm{OH}$, while their effective absorption cross sections are only some 3 orders of magnitude lower than that of $\mathrm{OH}$. Thus stronger absorption features are usually obtained. Moreover, the much wider vibronic bands of the polyatomic molecules require a considerably lower spectral resolution (about $0.5 \mathrm{~nm}$, compared to $\simeq 0.003 \mathrm{~nm}$ for the $\mathrm{OH}$ spectrometer). As a consequence, not only can a smaller spectrometer (SPEX 1870, 0.5-m focal length) be used, but also a $\mathrm{Xe}$-arc lamp is sufficient as light source.

Two spectral regions $\left(286-314 \mathrm{~nm}\right.$ for $\mathrm{SO}_{2}$ and 321-349 $\mathrm{nm}$, containing a series of bands from $\mathrm{NO}_{2}, \mathrm{O}_{3}$, and $\mathrm{CH}_{2} \mathrm{O}$ ) were alternatingly scanned for about $5 \mathrm{~min}$ and $15 \mathrm{~min}$, respectively. The integration times were chosen to keep the photon statistics dominated amplitude noise in the spectra sufficiently low to allow determination of trace gas concentrations with less than $10 \%$ error. Thus a complete set of the four trace gas concentrations was measured every $20 \mathrm{~min}$.

\section{Hydrocarbon Measurements}

Grab samples for hydrocarbon analysis were taken at the Schauinsland site (see Figure 2). Because of the limited availability of sampling containers (21, stainless steel) samples could be drawn only once or twice a day. In the laboratory those samples were analyzed by gas chromatography (GC) for $\mathrm{C}_{2}-\mathrm{C}_{5}$ alkanes and olefines as well as for $\mathrm{C}_{2} \mathrm{H}_{2}$ [c.f. Rudolph et al., 1981]. Concentrations of some benzene derivatives and terpene species were also measured. Analysis took place within 9-16 days after sampling. The error of the GC analysis is estimated at $\pm 10 \%$. The light alkanes and olefines are known to show negligible decay on time scales of weeks, thus the total error in the concentration of those species is given by the error of the GC analysis. In the case of terpenes, however, during experiments with the type of sample container used for the measurements reported here, concentrations decreased by $0-50 \%$ within 2 weeks. Thus the error of the terpene measurements is estimated at $+100 \% /-10 \%$.

Unfortunately, the samples taken during the time period of the $\mathrm{OH}$ measurements were not analyzed for carbon monoxide and methane. However, from later campaigns performed at the same site during May 1985 and June 1986, simultaneous hydrocarbon, $\mathrm{CO}$, and $\mathrm{CH}_{4}$ data are available (J. Rudolph, unpublished data, 1987). Carbon monoxide and acetylene have similar atmospheric residence times, and the anthropogenic portion of $\mathrm{CO}$ originates from essentially the same sources as $\mathrm{C}_{2} \mathrm{H}_{2}$, thus both species are fairly well correlated. The regression curve in a $\mathrm{C}_{2} \mathrm{H}_{2}-\mathrm{CO}$ plot constructed from the 1985/1986 data can be expressed by

$$
[\mathrm{CO}]=(215 \pm 18)+(53 \pm 12)\left[\mathrm{C}_{2} \mathrm{H}_{2}\right]
$$

with quantities in square brackets indicating mixing ratios in $\mathrm{ppb}$. More than $68 \%$ of the observed $\mathrm{CO}$ mixing ratios were within $\pm 60 \mathrm{ppb}( \pm 1 \sigma)$ of the value given by (1).

The $\mathrm{CH}_{4}-\mathrm{C}_{2} \mathrm{H}_{2}$ correlation is much weaker but nevertheless statistically significant; it can be expressed by

$$
\left[\mathrm{CH}_{4}\right]=(1811 \pm 16)+(24 \pm 10)\left[\mathrm{C}_{2} \mathrm{H}_{2}\right]
$$

with $>68 \%$ of the observed $\mathrm{CH}_{4}$ mixing ratios within \pm 46 $\mathrm{ppb}( \pm 1 \sigma)$ of the value given by (2).

The $\mathrm{CO}$ and $\mathrm{CH}_{4}$ mixing ratios during June 1984 were estimated from (1) and (2) using the $\mathrm{C}_{2} \mathrm{H}_{2}$ values measured in 1984. 
In addition to those grab samples, formaldehyde concentrations were measured by bringing air into contact with an aqueous 2,4-dinitrophenyl-hydrazine solution and selectively detecting the resulting 2,4-dinitrophenyl-hydrazone by high-pressure liquid chromatography (HPLC) [Lowe et al., $1980 ;$ Schubert, 1987]. Sampling time was between 30 and 60 min; the resulting samples were analyzed for $\mathrm{CH}_{2} \mathrm{O}$ on site within 24 hours.

\section{Absolute Measurement of Photolysis Frequencies}

Two photoelectric detectors observing the solar radiation fluxes in the wavelength ranges $290-315 \mathrm{~nm}$ and $300-420 \mathrm{~nm}$, respectively, were used to determine the photolysis frequencies of ozone, $J\left(\mathrm{O}_{3}\right)$, and nitrogen dioxide, $J\left(\mathrm{NO}_{2}\right)$ :

$$
\begin{gathered}
\mathrm{O}_{3}+h \nu \rightarrow \mathrm{O}_{2}+\mathrm{O}\left({ }^{1} D\right) \\
\mathrm{NO}_{2}+h \nu \rightarrow \mathrm{NO}+\mathrm{O}\left({ }^{3} P\right)
\end{gathered}
$$

Both detectors were equipped with scattering devices, giving less than 5\% deviation from an uniform angular response for direct and scattered $\mathrm{UV}$ radiation at zenith angles between $0^{\circ}$ and $90^{\circ}$ (W. Junkermann, U. Platt, and A. Volz, A photoelectric detector for the measurement of photolysis frequencies of ozone and other atmospheric molecules, submitted to the Journal of Atmospheric Chemistry, 1988; hereafter called Junkermann et al., submitted manuscript, 1988). In order to match the detector responses to the photoactinic spectra $P(\lambda)$ of (3) and (4), respectively, special filters were used. The photoactinic spectrum of a photochemical reaction is obtained by multiplying the wavelength-dependent absorption cross section $\sigma(\lambda)$ of the photolyzed molecule $\left(\mathrm{O}_{3}\right.$ or $\mathrm{NO}_{2}$ ) with the quantum yield $\Phi(\lambda)$ for the reaction channel of interest:

$$
P(\lambda)=\sigma(\lambda) \Phi(\lambda)
$$

In the case of the $J\left(\mathrm{O}_{3}\right)$ detector, a combination of a solar blind photomultiplier tube (Hamamatsu model 431S) with an interference filter was used to match $P(\lambda)$ for $\lambda=290-320$ $\mathrm{nm}$. For the $J\left(\mathrm{NO}_{2}\right)$ detector, a blue-sensitive vacuum photodiode (Hamamatsu R-488-02), together with a set of color glass filters served the same purpose.

For absolute calibration the $J\left(\mathrm{O}_{3}\right)$ sensor was exposed to solar radiation side by side with a chemical actinometer. Comparison of the actinometer response with the $J\left(\mathrm{O}_{3}\right)$ sensor signal time integrated over the exposure time under a variety of solar zenith angles resulted in a calibration curve. From that procedure an accuracy of $\pm 13 \%$ for $J\left(\mathrm{O}_{3}\right)$ was determined (Junkermann et al., submitted manuscript, 1988).

The response of the $J\left(\mathrm{NO}_{2}\right)$ sensor was scaled to the empirical correlation of $J\left(\mathrm{NO}_{2}\right)$ to the total radiation intensity at small to medium zenith angles reported by $B$ ahe et al. [1980]. From the regression analysis of these authors and from the stated error of their $J\left(\mathrm{NO}_{2}\right)$ determination, an uncertainty in our $J\left(\mathrm{NO}_{2}\right)$ data of $\pm 15 \%$ is estimated. The total radiation intensity was continuously recorded as a part of the meteorological observations by a calibrated sensor (Kipp \& Zonen CM 6).

\section{Aerosol Measurements}

Atmospheric aerosol concentrations were monitored by two instruments. First, commercial condensation nuclei
(CN) counter (TSI, model 3020) was used to detect particles with diameters greater than $0.01 \mu \mathrm{m}$. Second, the total light-scattering cross section $(\beta)$ of larger $(d \geq 0.1 \mu \mathrm{m})$ particles was recorded by an integrating nephelometer, which measured the amount of light scattered from a $\mathrm{He}$ Ne-laser $(\lambda=632.8 \mathrm{~nm})$ beam. The instrument was calibrated by observing the Rayleigh scattering of aerosol free gases (air and $\mathrm{CCl}_{2} \mathrm{~F}_{2}$ ) with different Rayleigh scattering cross sections, as described by Charlson et al. [1969]. Taking the Rayleigh scattering cross sections for the above gases from Harrison [1977], the total effective cross section of the atmospheric aerosol could be determined.

It should be noted that (for a given aerosol size distribution) the total aerosol surface area per unit volume, $A$, is proportional to the light-scattering coefficient, $\beta$, as measured by the nephelometer:

$$
A=Q_{s}(\lambda, d) F \beta \quad\left(m^{2} / m^{3}\right)
$$

For particles with diameters $d>0.1 \mu \mathrm{m}$, the scattering efficiency $Q_{s}(\lambda, d)$ rapidly rises from zero to near unity at $d>$ $0.3 \mu \mathrm{m}$ (see, for instance, Twomey, [1977]). Therefore the nephelometer effectively is sensitive only to particles larger than $0.1-0.3 \mu \mathrm{m}$. The factor $F$ indicates the ratio of the particle surface and its cross section. In the case of spherical particles, $F=4$; for particles of nonspherical shape the value of $F$ will be larger. Thus taking $Q_{s}(\lambda, d)$ as unity, $A \simeq 4 \beta$ will be a lower limit to the total aerosol surface.

\section{Meteorologic Observations}

Wind speed and direction, temperature, relative humidity, air pressure, rainfall, and total radiation were continuously monitored and recorded by a computer-controlled data acquisition system at the Schauinsland site. The meteorological measurements were made with commercially available sensors. In addition to that, local $\mathrm{O}_{3}$ concentrations were measured by a short-path UV absorption technique (DASIBI). Supporting data were also supplied by the Bundesamt für Zivilschutz, which measured 1-hour integrated ${ }^{222} \mathrm{Rn}$ concentrations at Freiburg ( $240 \mathrm{~m}$ above sea level) as well as at the Schauinsland site [Weiss et al., 1985; Weiss, private communication, 1987].

\section{Siting of Instruments in the Field}

Most of the experiments were sited near the top of the Schauinsland mountain in the Black Forest $(1220 \mathrm{~m}$ above sea level). The region is mostly forested (coniferous trees), except for the areas at the bottom of the valleys and the top of Feldberg mountain, which extends above the tree line at about $1350 \mathrm{~m}$. All in situ measurements: meteorologic observations, aerosol measurements, collection of hydrocarbon samples, and the spectrometers of the two LPA experiments were located at the Schauinsland site. For the $\mathrm{OH}$ LPA experiment, laser and spectrometer were placed side by side in the basement of a tower belonging to a solar observatory station (Kiepenheuer Institute). The DOAS spectrometer was housed in a small shed at some $100 \mathrm{~m}$ distance from the tower.

Initially, both the reflecting mirror for the $\mathrm{OH}$ experiment and the Xe-arc light source of the DOAS instrument were installed at the Feldberg weather station ( $1480 \mathrm{~m}$ above sea level). Thus the total light path lengths were $17.2 \mathrm{~km}$ for the $\mathrm{OH}$ experiment and $8.6 \mathrm{~km}$ for the DOAS instrument, 


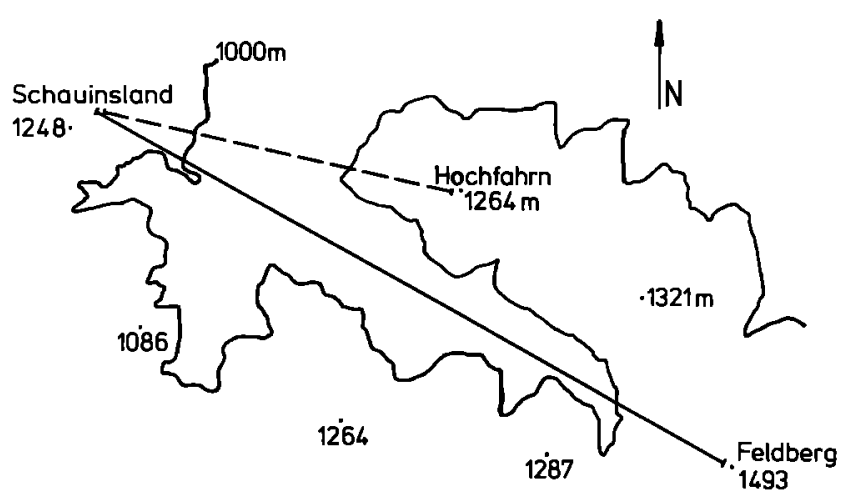

Fig. 2. Arrangement of the light paths of the two LPA experiments. The laser beam of the $\mathrm{OH}$ experiment originates at the Schauinsland ( $1220 \mathrm{~m}$ above sea level), is reflected by a mirror at the Hochfahrn $(1240 \mathrm{~m})$ at $4.3-\mathrm{km}$ distance, and is received at the Schauinsland. The DOAS light beam is emitted by a Xe-arc searchlight at the Feldberg weather station $(1480 \mathrm{~m})$ and observed at the Schauinsland. For comparison, the $1000-\mathrm{m}$ height contour along the valley is also given. The total length of both light paths is $8.6 \mathrm{~km}$.

respectively. While this arrangement provided optimum conditions for the DOAS instrument, the 17.2- $\mathrm{km}$ light path was found to be too long for the visibility conditions encountered during early June, when the instruments were installed. It was therefore decided to cut the $\mathrm{OH}$ light path length in half by relocating the reflecting mirror to a site near the top of Hochfahrn mountain $(1240 \mathrm{~m})$ at $4.3-\mathrm{km}$ distance from the Schauinsland. Because of space limitations it was impossible to move the DOAS spectrometer to the site of the $\mathrm{OH}$ spectrometer, thus the DOAS light path had to remain unchanged.

The map in Figure 2 shows the final arrangement of the two light paths as it was used during all measurements reported in this publication. The light paths were running in east-southeasterly $(\mathrm{OH})$ and southeasterly (DOAS) directions, respectively, forming an angle of about $16^{\circ}$. The horizontal distance between the far end of the $\mathrm{OH}$ light path at the Hochfahrn site and the DOAS light path was $1.2 \mathrm{~km}$. In Figure 3, vertical cross sections of the terrain along the two light paths are shown. The two light paths are running at average heights of 1230 and $1350 \mathrm{~m}$ above sea level. As can be seen from the 1000-m-height contour line in Figure 2, both light paths traverse a fairly deep valley. Thus large fractions of the paths are more than $300-500 \mathrm{~m}$ above the ground. Moreover, since both light paths run at or above the height of the tops of the highest surrounding mountains (between

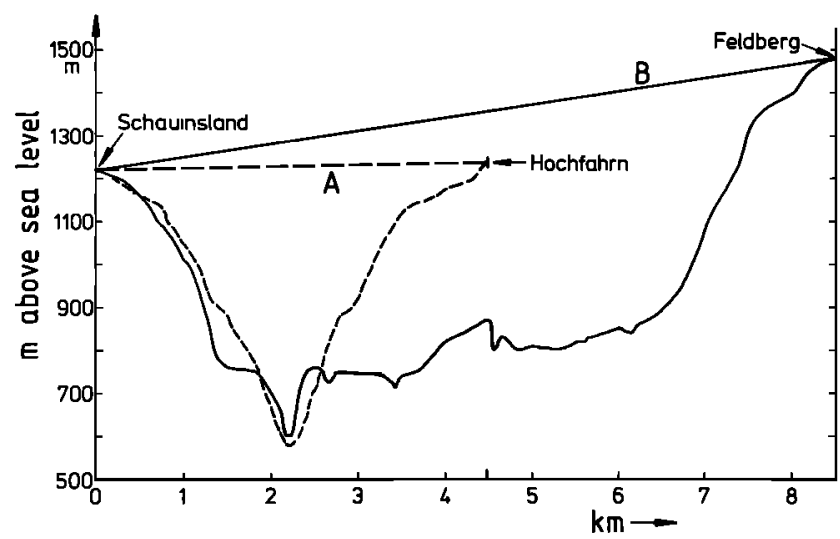

Fig. 3. Terrain cross section along the two light paths.
1086 and $1321 \mathrm{~m}$, as indicated by dots in Figure 2), the measurements should be undisturbed by direct influence from the ground.

\section{Results}

The ultraviolet spectra showed definite $\mathrm{OH}$ absorption features yielding $\mathrm{OH}$ concentrations from $<1.5 \times 10^{6}$ to 8.7 $\times 10^{6} \mathrm{~cm}^{-3}$.

The detection limits obtained at most of the measurements were not as good as the best values reached in earlier campaigns [Perner et al., 1987]. This was due to less than ideal visibility conditions, with UV attenuation lengths of the order of $5 \mathrm{~km}$, as well as to the occurrence of unidentified absorption features in the $\mathrm{OH}$ spectra. Although those features occured at spectral positions different from $\mathrm{OH}$, they were included in the estimation of the error limits, as described above.

Table 1 gives the results of all $\mathrm{OH}$ measurements, together with the supporting spectroscopic and HPLC trace gas observations, photolysis frequency, aerosol, and meteorological data. All data in Table 1 are averages over the time intervals of the $\mathrm{OH}$ measurements. The table also contains an interesting example of an $\mathrm{OH}$ diurnal cycle. It is shown explicitly in Figure 4, together with profiles of $J\left(\mathrm{O}_{3}\right), \mathrm{NO}_{2}$, and $\mathrm{CH}_{2} \mathrm{O}$ measured during June 25,1984 . The observed $\mathrm{OH}$ concentrations vary between about $2 \times 10^{6} \mathrm{~cm}^{-3}$ in the morning or evening hours up to peak values around $6 \times 10^{6}$ $\mathrm{cm}^{-3}$ between $\simeq 1130$ and $\simeq 1500$ Central European Time (CET). Thus the $\mathrm{OH}$ levels roughly follow the measured photolysis frequency of ozone (dashed line), which is the main source of tropospheric $\mathrm{OH}$. Mixing ratios of $\mathrm{NO}_{2}$ and $\mathrm{CH}_{2} \mathrm{O}$ (measured by DOAS) ranged from 0.4 to $1.0 \mathrm{ppb}$ and $\simeq 0.3$ to $0.7 \mathrm{ppb}$, respectively. In situ $\mathrm{CH}_{2} \mathrm{O}$ levels were about a factor of 2 higher, ranging from 0.8 to $1.4 \mathrm{ppb}$. The $\mathrm{O}_{3}$ mixing ratio as measured by DOAS stayed fairly constant during that day at $49 \pm 2 \mathrm{ppb}$, while the DASIBI $\mathrm{O}_{3}$ data (which are representative for air close to the ground) showed a slight increase, from 39 to $46 \mathrm{ppb}$ between 0900 and 1600 CET. The results of the gas chromatographic analysis of the grab samples are presented in Table 2. Also included are the $\mathrm{CO}$ and $\mathrm{CH}_{4}$ levels estimated from measured $\mathrm{C}_{2} \mathrm{H}_{2}$ and the CO- $\mathrm{C}_{2} \mathrm{H}_{2}$ and $\mathrm{CH}_{4}-\mathrm{C}_{2} \mathrm{H}_{2}$ correlations, as described above. Figure 5 shows the time series of total radiation intensity, $J\left(\mathrm{O}_{3}\right), J\left(\mathrm{NO}_{2}\right)$, concentration of $\mathrm{CN}$ and the aerosol lightscattering signal $(\beta)$ as well as DASIBI $\mathrm{O}_{3}$ data for the time period of the $\mathrm{OH}$ measurements (June 19 to 26).

During the entire campaign, $\mathrm{NO}_{2}$ mixing ratios ranged from 0.4 to $2.5 \mathrm{ppb}$, and $\mathrm{SO}_{2}$ ratios ranged from 0.7 to 2.3 $\mathrm{ppb}$. Formaldehyde levels always exceeded the detection limits $(0.1 \mathrm{ppb})$ of the in situ (HPLC) and long-path absorption (DOAS) techniques. The DOAS data ranged from 0.3 to $3.5 \mathrm{ppb}$, while the in situ measurements always gave equal or higher values, ranging from 0.8 to $3.8 \mathrm{ppb}$.

Ozone mixing ratios measured by DOAS ranged from 25 to $104 \mathrm{ppb}$; however, most values stayed close to the average of all values of $57 \mathrm{ppb}$. In situ $\mathrm{O}_{3}$ levels, as measured by the DASIBI instrument at Schauinsland, varyed from 39 to 75 $\mathrm{ppb}$, averaging $52 \mathrm{ppb}$. Except for the small systematic difference (the in situ data are $=10 \%$ lower compared to the DOAS measurements), which could be due to the influence of $\mathrm{O}_{3}$ destruction at the ground, both data sets are in satisfactory agreement. 
TABLE 1. OH Concentrations and Supporting Data Measured in the Black Forest

\begin{tabular}{|c|c|c|c|c|c|c|c|c|c|c|c|c|c|c|}
\hline $\begin{array}{l}\text { Measurement } \\
\text { Number }\end{array}$ & $\begin{array}{l}\text { Time, } \\
\text { CET }\end{array}$ & $\begin{array}{c}\mathrm{OH}, 10^{6} \\
\text { molecules } \\
\mathrm{cm}^{-3}\end{array}$ & $\begin{array}{l}\mathrm{O}_{3}, * \\
\mathrm{ppb}\end{array}$ & $\begin{array}{l}\mathrm{O}_{3} \\
\mathrm{ppb}\end{array}$ & $\begin{array}{c}J\left(\mathrm{O}_{3}\right) \\
10^{-5} \\
\mathrm{~s}^{-1}\end{array}$ & $\begin{array}{c}J\left(\mathrm{NO}_{3}\right) \\
10^{-3} \\
\mathrm{~s}^{-1}\end{array}$ & $\begin{array}{c}\mathrm{H}_{2} \mathrm{O} \\
10^{17} \\
\mathrm{~cm}^{-3}\end{array}$ & $\begin{array}{l}\text { Temper- } \\
\text { ature, } \\
{ }^{\circ} \mathrm{C}\end{array}$ & $\begin{array}{l}\mathrm{SO}_{2}, \\
\mathrm{ppb}\end{array}$ & $\begin{array}{l}\mathrm{NO}_{2} \\
\mathrm{ppb}\end{array}$ & $\begin{array}{c}\mathrm{CH}_{2} \mathrm{O} \\
\mathrm{ppb}\end{array}$ & $\begin{array}{c}\mathrm{CH}_{2} \mathrm{O}, * \\
\mathrm{ppb}\end{array}$ & $\begin{array}{l}\mathrm{CN} \\
\mathrm{cm}^{-3}\end{array}$ & $\begin{array}{c}\beta, \\
10^{-4} \\
\mathrm{~m}^{-1}\end{array}$ \\
\hline \multicolumn{15}{|l|}{ June 19,1984} \\
\hline 1 & $0846-0948$ & $<5.9$ & 58 & 75 & 1.2 & 6.1 & 3.02 & 18.6 & 1.5 & 1.1 & 1.6 & 2.1 & 700 & 0.71 \\
\hline 2 & $0949-1056$ & $<5.0$ & 62 & 66 & 1.9 & 6.7 & 3.26 & 20.5 & 1.2 & 1.8 & 1.4 & 3.1 & 1090 & 0.84 \\
\hline 3 & $1106-1222$ & $3.0 \pm 3.7$ & 65 & 75 & 2.5 & 6.8 & 3.53 & 21.6 & 1.9 & 2.3 & 1.9 & 3.8 & 1550 & 0.97 \\
\hline 4 & $1225-1428$ & $8.0 \pm 6.3$ & 75 & 104 & 2.3 & 6.5 & 3.49 & 22.0 & 2.3 & 2.2 & 3.5 & 3.6 & 1670 & 0.98 \\
\hline \multicolumn{15}{|l|}{ June 20,1984} \\
\hline 5 & $0827-0921$ & $6.2 \pm 4.0$ & 65 & 69 & 1.2 & 6.2 & 2.57 & 18.5 & 0.8 & 0.5 & 0.6 & 1.7 & 720 & 0.89 \\
\hline 6 & $0923-1118$ & $8.7 \pm 6.9$ & 68 & 70 & 1.9 & 6.8 & 2.92 & 21.0 & 0.7 & 0.4 & 0.6 & 1.9 & (870) & 0.95 \\
\hline \multicolumn{15}{|l|}{ June 25,1984} \\
\hline 7 & $0843-0935$ & $<2.5$ & 39 & 51 & 1.3 & 7.2 & 1.74 & 9.8 & $\cdots$ & $\cdots$ & $\cdots$ & 0.8 & 480 & 0.49 \\
\hline 8 & $0957-1045$ & $2.9 \pm 1.5$ & 40 & 50 & 2.3 & 8.2 & 1.89 & 10.5 & 0.2 & 0.4 & $\cdots$ & 0.9 & 1050 & 0.57 \\
\hline 9 & $1050-1117$ & $5.0 \pm 1.0$ & 41 & 49 & 2.9 & 8.8 & 1.86 & 10.5 & 0.5 & 0.63 & 0.63 & 0.9 & 1900 & 0.54 \\
\hline 10 & $1125-1223$ & $5.7 \pm 1.9$ & 42 & 49 & 2.4 & 6.7 & 1.78 & 10.2 & 0.8 & 1.0 & 0.33 & 1.1 & 2250 & 0.56 \\
\hline 11 & $1223-1306$ & $6.3 \pm 2.0$ & 43 & 47 & 2.9 & 7.8 & 1.91 & 11.6 & 0.9 & 0.81 & 0.42 & 1.3 & 2100 & 0.58 \\
\hline 12 & $1307-1407$ & $6.2 \pm 1.5$ & 46 & 50 & 2.6 & 7.3 & 1.94 & 11.0 & 0.7 & 0.59 & 0.59 & 1.4 & 1550 & 0.58 \\
\hline 13 & $1408-1503$ & $5.6 \pm 1.2$ & 47 & $\cdots$ & 1.9 & 6.6 & 1.99 & 10.5 & 0.7 & 0.54 & 0.68 & 1.2 & 1170 & 0.59 \\
\hline 14 & $1559-1635$ & $2.1 \pm 1.4$ & 46 & 48 & 0.7 & 3.5 & 2.23 & 11.2 & 1.1 & 0.75 & 0.73 & 1.1 & 1430 & 0.62 \\
\hline \multicolumn{15}{|l|}{ June 26,1984} \\
\hline 15 & $1104-1227$ & $<4.8$ & 42 & 28 & 1.8 & 5.2 & 2.90 & 14.0 & 2.5 & 2.5 & 1.6 & 1.5 & 1090 & 1.00 \\
\hline 16 & $1230-1313$ & $4.5 \pm 4.1$ & 47 & 47 & 2.0 & 5.8 & 2.81 & 14.7 & 2.6 & 2.2 & 1.2 & 1.5 & 1180 & 0.91 \\
\hline 17 & $1314-1423$ & $<2.6$ & 50 & 53 & 2.0 & 6.0 & 2.91 & 15.5 & 2.0 & 1.8 & 1.1 & 1.6 & 1200 & 0.87 \\
\hline 18 & $1425-1503$ & $<2.3$ & 49 & 50 & 1.9 & 6.6 & 2.90 & 16.2 & 2.7 & 1.6 & 1.3 & 1.6 & 1220 & 0.79 \\
\hline 19 & $1514-1621$ & $<1.8$ & 51 & 53 & 1.2 & 6.1 & 2.84 & 16.7 & 2.3 & 1.6 & 1.2 & 1.7 & 1150 & 0.85 \\
\hline 20 & $1622-1654$ & $<1.5$ & 54 & 53 & 0.7 & 4.9 & 2.81 & 17.1 & 2.3 & 1.6 & 1.2 & 2.0 & 1070 & 0.82 \\
\hline
\end{tabular}

*In situ data $\left(\mathrm{O}_{3}\right.$ : DASIBI, $\mathrm{CH}_{2} \mathrm{O}:$ HPLC).

Diurnal profiles of Rn at Freiburg showed a decrease (from 4-12 $\mathrm{Bq} \mathrm{m}{ }^{-3}$ ) starting at 0800 to 0900 CET (down to $1.8-4.5$ $\mathrm{Bq} \mathrm{m}^{-3}$ ) until around $1500 \mathrm{CET}$. At the same time at the Schauinsland site, $\mathrm{Rn}$ levels increased (from $0.4-2.0 \mathrm{~Bq}$ $\mathrm{m}^{-3}$ ) to levels slightly below those at Freiburg until and after 1200-1300 CET (W. Weiss, private communication, 1987).

\section{Discussion}

The final purpose of the described measurements was to perform a test of the proposed photochemical reaction mechanisms related to sources, transformation pathways, and sinks of $\mathrm{OH}$ radicals in the atmosphere. The first step in any meaningful test of photochemical theory is the acquisi-

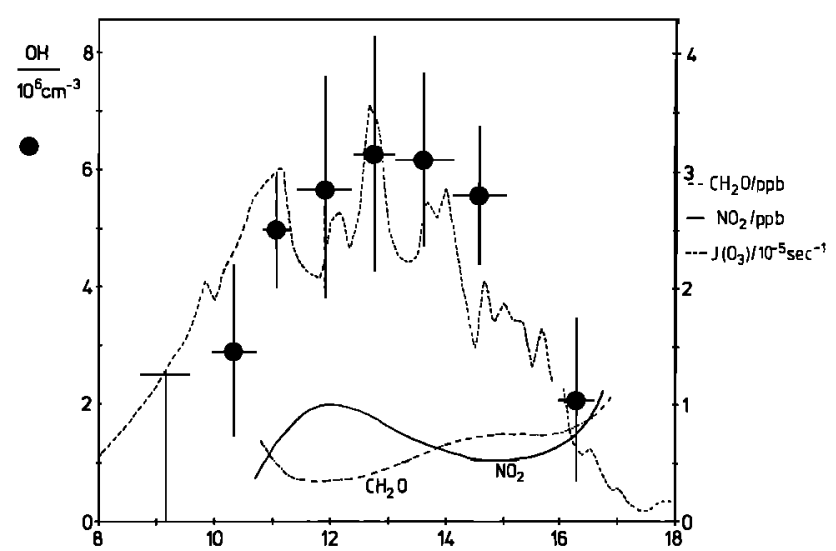

Fig. 4. Diurnal profiles of $\mathrm{OH}$ (solid circles), $\mathrm{NO}_{2}$ (solid line), $\mathrm{CH}_{2} \mathrm{O}$ (dashed-dotted line), and ozone photolysis frequency (dashed line) on June 25,1984 . Horizontal bars indicate the averaging time intervals; vertical bars give $1 \sigma$ errors of the measured $\mathrm{OH}$ concentrations. tion of a simultaneous data base of $\mathrm{OH}$ and supporting parameters in the same air mass.

In the sunlit atmosphere the steady state $\mathrm{HO}_{x}$ radical concentration is established in less than $1 \mathrm{~min}$. This has two important consequences. First, transport processes can be largely neglected in the model calculations. Second, because of the local nature of the $\mathrm{HO}_{x}$ radical chemistry, local values, rather than regional or even global averages for the model input parameters, must also be known. Ideally therefore, all measurements should be done at one point in space. In practice, of course, this is usually not possible.

\section{Spatial and Temporal Coherence of Data Set}

The measurements of the various parameters described in this publication had different degrees of spatial extension. Meteorologic data, $\mathrm{O}_{3}$ (DASIBI), and photolysis frequencies were measured in situ with a spatial separation between individual instruments of the order of meters. The $\mathrm{OH}$ concentrations were averaged over a $4.3-\mathrm{km}$ light path, and DOAS data over a $8.6-\mathrm{km}$ path (see Figures 2, 3). While the $\mathrm{OH}$ light path was essentially level, extending from $1220 \mathrm{~m}$ above sea level (Schauinsland) to $1240 \mathrm{~m}$ (Hochfahrn), the light beam of the DOAS experiment was crossing the height interval from 1220 to $1480 \mathrm{~m}$ (Feldberg). Thus part of the measured data are actually averages over quite large volumes of air, which could render the measured values difficult to treat by model calculations if the trace gas distributions in the investigated air masses were very inhomogeneous.

In the following, we shall discuss the degree of spatial variations to be expected across the horizontal and vertical extensions of the measuring volumes. First, the decrease of the $\mathrm{Rn}$ levels observed at Freiburg indicates a continuous 
TABLE 2. CO and Hydrocarbon Mixing Ratios

\begin{tabular}{|c|c|c|c|c|c|c|}
\hline \multirow[b]{2}{*}{ Species } & \multirow{2}{*}{$\begin{array}{c}\text { June } 19 \\
(1041) \\
2^{*}\end{array}$} & \multirow{2}{*}{$\begin{array}{c}\text { June } 20 \\
(1025) \\
6^{*}\end{array}$} & \multicolumn{2}{|c|}{ June 25} & \multicolumn{2}{|c|}{ June 26} \\
\hline & & & $\begin{array}{c}(1025) \\
8^{*}\end{array}$ & $\begin{array}{c}(1220) \\
10^{*}\end{array}$ & $\begin{array}{c}(1225) \\
15^{*}\end{array}$ & (1930) \\
\hline $\mathrm{CH}_{4}^{\dagger}$ & 1880. & 1840. & 1820. & 1820. & 1870. & $\cdots$ \\
\hline $\operatorname{co} \dagger$ & 360. & 270 . & 230. & 230 . & 350. & $\cdots$ \\
\hline $\mathrm{C}_{2} \mathrm{H}_{4}$ & 3.77 & 2.05 & 1.07 & 0.76 & 1.80 & $\cdots$ \\
\hline $\mathrm{C}_{2} \mathrm{H}_{2}$ & 2.81 & 1.04 & 0.29 & 0.19 & 2.60 & $\cdots$ \\
\hline $\mathrm{C}_{2} \mathrm{H}_{6}$ & 2.69 & 1.80 & 1.97 & 2.05 & 1.92 & $\cdots$ \\
\hline $\mathrm{C}_{3} \mathrm{H}_{6}$ & 0.87 & 1.34 & 0.43 & 0.20 & 0.31 & $\cdots$ \\
\hline $\mathrm{C}_{3} \mathrm{H}_{8}$ & 0.97 & 0.75 & 0.39 & 0.52 & 0.63 & $\cdots$ \\
\hline$i \mathrm{C}_{4} \mathrm{H}_{10}$ & 0.97 & 0.31 & 0.18 & 0.14 & 0.35 & $\cdots$ \\
\hline $\mathrm{C}_{4} \mathrm{H}_{8}$ & 0.09 & 0.30 & 0.08 & 0.04 & 0.09 & $\cdots$ \\
\hline$n \dot{\mathrm{C}}_{4} \mathrm{H}_{10}$ & 3.06 & 1.06 & 0.42 & 0.37 & 1.02 & $\cdots$ \\
\hline$i \mathrm{C}_{5} \mathrm{H}_{12}$ & 1.54 & 0.44 & 0.29 & 0.13 & 0.36 & $\cdots$ \\
\hline$n \mathrm{C}_{5} \mathrm{H}_{12}$ & 1.29 & 0.48 & 0.15 & 0.14 & 0.41 & $\cdots$ \\
\hline$n \mathrm{C}_{6} \mathrm{H}_{14}$ & 0.84 & 0.19 & $\cdots$ & 0.70 & $\cdots$ & 0.07 \\
\hline Benzene & 1.05 & 0.23 & 0.09 & 0.20 & 0.60 & 0.33 \\
\hline Toluene & 2.08 & 0.56 & 0.24 & 0.28 & 0.31 & 0.48 \\
\hline Ethylbenzene & 0.47 & 0.12 & 0.09 & 0.10 & 0.10 & 0.08 \\
\hline$p, m$ Xylene & 0.67 & 0.17 & 0.08 & 0.18 & 0.11 & 0.11 \\
\hline$o$-Xylene & 0.35 & 0.08 & 0.03 & 0.05 & 0.02 & $\cdots$ \\
\hline$\alpha$-Pinene & 0.080 & 0.011 & $\ldots$ & 0.005 & 0.010 & 0.004 \\
\hline Terpinene & 0.052 & 0.031 & $\cdots$ & 0.017 & 0.012 & 0.012 \\
\hline Limonene & 0.057 & 0.011 & $\cdots$ & 0.014 & 0.012 & 0.014 \\
\hline
\end{tabular}

Ratios are given in parts per billion. Time of measurement (Central European Time) is given in parentheses.

*Number of $\mathrm{OH}$ measurement in Table 1 during which the grab sample was taken.

†Data estimated from the $\mathrm{C}_{2} \mathrm{H}_{2}-\mathrm{CO}$ and $\mathrm{C}_{2} \mathrm{H}_{2}-\mathrm{CH}_{4}$ correlations, respectively (see text).

increase of the inversion height, starting between 0800 and 0900 CET and continuing until mid-afternoon $(\sim 1500)$. Therefore during the morning hours, all measurements are likely to take place in the free atmosphere above the boundary layer. At or shortly after noon (1200-1300), the inversion height exceeds the level of the Schauinsland site $(1220 \mathrm{~m})$. From those data the rate of increase of the inversion height during mornings and mid-afternoons can be estimated at 200-300 $\mathrm{m} \mathrm{h}^{-1}$. Thus for about 1 hour, the DOAS light path is partly above and partly below the inversion height. After 1300-1400 CET, the inversion height exceeds $1500 \mathrm{~m}$, and all experiments are now probing the air within the boundary layer.

The worst case vertical concentration gradients of the measured trace gases during the "critical time" when the DOAS light path intersects the inversion can be estimated from the changes in concentration between 1200 to 1400 CET. As can be seen from Table $1, \mathrm{O}_{3}, \mathrm{SO}_{2}, \mathrm{NO}_{2}$, and $\mathrm{CH}_{2} \mathrm{O}$ changed by less than a factor of 2 during that period. At times, when all measurements take place entirely above or below the inversion, vertical gradients can be expected to be much smaller.

Compared to those possible deviations of the pathaveraged (DOAS) data from in situ values due to vertical concentration gradients, the influence of horizontal gradients is likely to be small. The horizontal gradients of the above trace gases can be estimated from their temporal variations and the wind speeds measured during the experiments. Resulting horizontal gradients of $\mathrm{SO}_{2}, \mathrm{NO}_{2}$, and $\mathrm{CH}_{2} \mathrm{O}$ are typically below $0.05 \mathrm{ppb} \mathrm{km}^{-1}$, corresponding to deviations below $\pm 0.25 \mathrm{ppb}$ from the average along the $\mathrm{OH}$ light path.

In the case of hydrocarbons from the data set presented in this publication, little can be said about possible diurnal variations. However, as mentioned above, during the campaign in June/July 1986, comprehensive hydrocarbon measurements were made, which resulted in about 30 complete diurnal profiles of light nonmethane hydrocarbon species ( $\mathrm{J}$.
Rudolph, unpublished data, 1987). Those data show usually little (less than $\pm 20 \%$ ) variation in the mixing ratios of the medium- to longer-lived hydrocarbon species $\left(\mathrm{C}_{2}-\mathrm{C}_{5}\right.$ alkanes and alkenes) during the time period of $\mathrm{OH}$ measurements, i.e., from midmorning to late afternoon. The same general weather and pollution pattern existed during summer 1984 and summer 1986. We therefore assume that the variations in $\mathrm{C}_{2}-\mathrm{C}_{5}$ alkane and alkene mixing ratios around noon were also small in 1984 and thus are sufficiently represented by one or two grab samples per day.

It has to be concluded that there are in fact noticeable deviations of the actually measured trace gas concentrations from the values which would be obtained in the ideal case of all measurements probing the same (small) volume of air. Those deviations are due to vertical concentration gradients and, to a lesser extent, to horizontal gradients. On the other hand, the effect of possible uncertainties in the values of the supporting parameters on the result of $\mathrm{OH}$ model calculations should not be overestimated. Although a rigorous sensitivity analysis will be the subject of a forthcoming publication, from the analysis by Perner et al. [1987], the sensitivity of modeled $\mathrm{OH}$ levels to the trace gases measured in this campaign can be estimated to be below $50 \%$. On the basis of those data, the maximum deviation between in situ and path-averaged data of a factor of 2 would propagate into uncertainties of the modeled $\mathrm{OH}$ below $25 \%$, which is of the order of the experimental uncertainties of the measured $\mathrm{OH}$ concentrations.

\section{Comparison With Results of Earlier Campaigns}

A detailed analysis of the present data set, in particular with respect to our present understanding of atmospheric photochemistry, will be the topic of a forthcoming publication. However, in order to allow easier interpretation of the experimental results, we shall discuss some aspects of the present data in the following. The atmospheric $\mathrm{OH}$ levels 


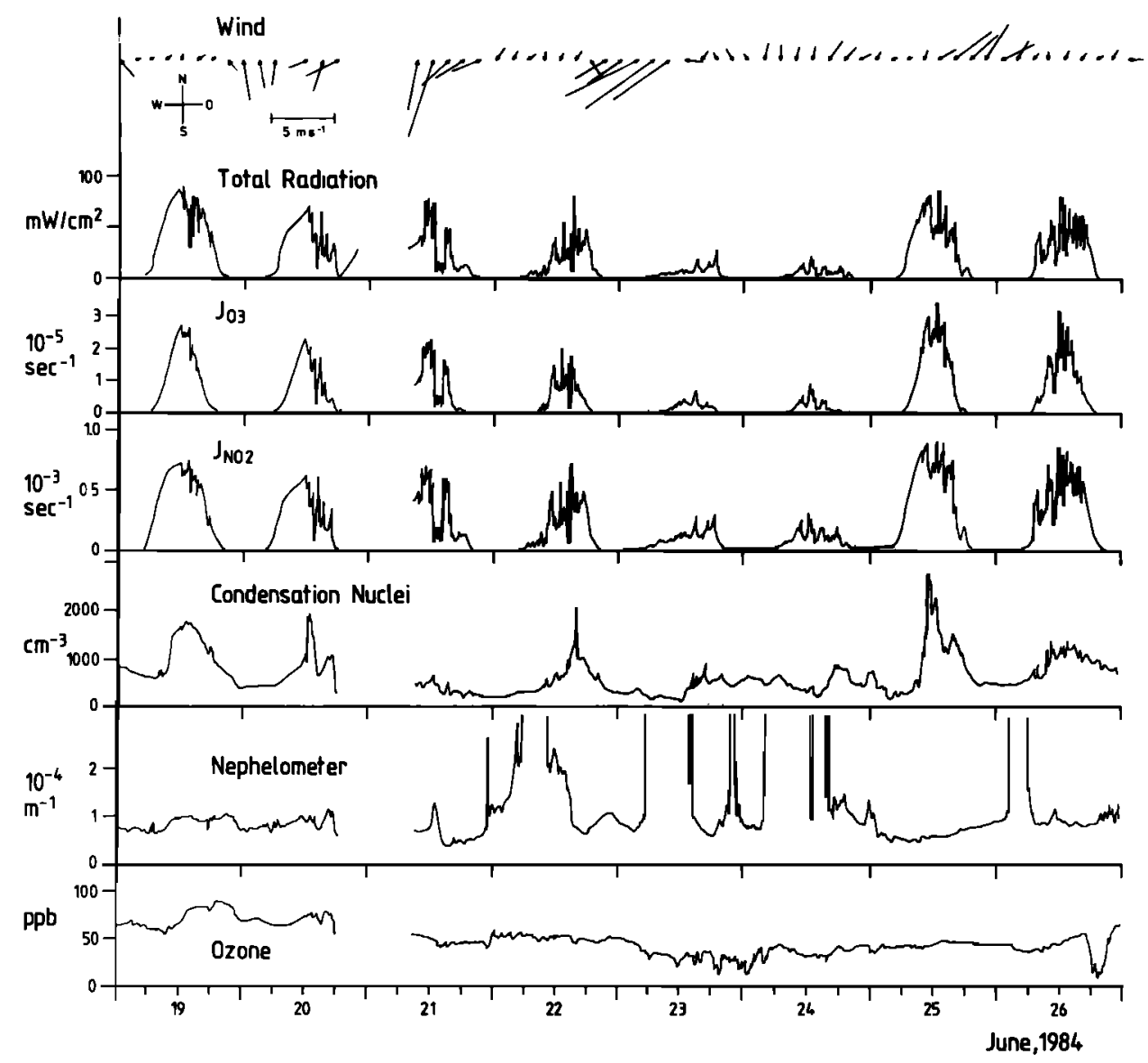

Fig. 5. Time series of total radiation, $J\left(\mathrm{O}_{3}\right), J\left(\mathrm{NO}_{2}\right)$, concentration of condensation nuclei $(\mathrm{CN})$, the aerosol light-scattering signal $(\beta)$, ozone (in situ data), and wind during June 19-26, 1984.

measured during this campaign are somewhat higher than those observed before with our laser long-path absorption technique. In earlier measurements, made at Jülich and Deuselbach between 1979 and 1983, measured OH concentrations usually stayed below $4-5 \times 10^{6} \mathrm{OH} \mathrm{cm}^{-3}[$ Perner et al., 1976, 1981 1987; Hübler et al. 1984].

A factor contributing to the observed high $\mathrm{OH}$ levels could be the large observed photolysis frequencies. On June 25 and June 26 , short-term peak values of $J\left(\mathrm{O}_{3}\right)$ and $J\left(\mathrm{NO}_{2}\right)$ reached $3.5 \times 10^{-5} \mathrm{~s}^{-1}$ and $9 \times 10^{-3} \mathrm{~s}^{-1}$, respectively. Interestingly, those values are higher than those measured during clear-sky conditions. This enhancement could be due to reflection of UV radiation by the slight variable cloud covers existing during those 2 days. During earlier campaigns at Jülich and Deuselbach, $J\left(\mathrm{O}_{3}\right)$ averaged over the time interval of the $\mathrm{OH}$ measurement never exceeded $1.9 \times 10^{-5} \mathrm{~s}^{-1}$, while the corresponding values at the present campaign ranged up to $2.9 \times 10^{-5} \mathrm{~s}^{-1}$. Although the older measurements [Perner et al., 1987] are less certain than the new data, it is clear that at least $J\left(\mathrm{O}_{3}\right)$ was some $50 \%$ higher during the Schauinsland campaign. This could be partly due to the smaller zenith angle at the time near summer solstice, when the present measurements were made. Also, the present measurements were took place at greater elevation (Schauinsland, $\simeq 1220 \mathrm{~m}$ above sea level) compared to $<450 \mathrm{~m}$ at the earlier measurements. From the height dependence of multiple-scattered solar UV radiation in the atmosphere [Meier and Anderson, 1982] an increase in $J\left(\mathrm{O}_{3}\right)$ of $10-20 \%$ between 450 and $1250 \mathrm{~m}$ above sea level can be estimated.

In addition to that, the observed $\mathrm{CH}_{2} \mathrm{O}$ levels were unusually high in comparison to the mixing ratios of other trace gases like $\mathrm{NO}_{2}$ and $\mathrm{SO}_{2}$. In particular, the $\mathrm{CH}_{2} \mathrm{O} / \mathrm{NO}_{2}$ ratio (both species measured by DOAS) ranged from 0.33 to 1.59 , with an average of 0.92 . At sites with comparable levels of pollution in Germany (Deuselbach, Dagebüll) this ratio ranged from $<0.01$ to 0.7 , averaging only 0.23 [see Platt and Perner, 1980]. Even in highly polluted areas (Los Angeles, Cologne), $\mathrm{CH}_{2} \mathrm{O} / \mathrm{NO}_{2}$ ratios never exceeded a value of 0.7 [Tuazon et al., 1980; Platt and Perner, 1980; Kessler, 1984] with averages from 0.2 to 0.5 . The high ratios observed in polluted areas probably reflect the relative emission rates of the two species. Since the atmospheric lifetime of $\mathrm{CH}_{2} \mathrm{O}$ is slightly shorter than that of $\mathrm{NO}_{2}$, a decrease of that ratio during transport to more remote sites like the Schauinsland would be expected. In contrast to that expectation, the average $\mathrm{CH}_{2} \mathrm{O} / \mathrm{NO}_{2}$ ratios observed on Schauinsland exceed even the highest values found in polluted areas. A possible explanation is formation of $\mathrm{CH}_{2} \mathrm{O}$ by photochemical degradation of hydrocarbons, either during transport or in situ. The latter possibility is supported by the observation that the $\mathrm{CH}_{2} \mathrm{O}$ levels measured in situ are systematically higher than the path-averaged concentrations.

Another well-known indicator for photochemical activity is the rate of ozone formation. At the times of high $\mathrm{OH}$ radical concentrations (June 19,20, and 25) significant $\mathrm{O}_{3}$ increases were also observed. In particular, during June 19 this trend can be observed in both DASIBI and DOAS ozone measurements (see Figure 5 and Table 1). For June 20, only two DOAS $\mathrm{O}_{3}$ measurements are available, but the DASIBI data show a clear increase from late morning throughout the afternoon. On June 25 , an $\mathrm{O}_{3}$ increase is only visible in the in situ $\mathrm{O}_{3}$ measurements. 
Condensation nuclei are also known to be formed as a consequence of photochemical reactions in the gas phase. As can be seen from Figure 5 the $\mathrm{CN}$ concentration frequently shows sharp peaks at noon or in the early afternoon, in particular on days with strong UV radiation. The highest peak (up to $1900 \mathrm{~cm}^{-3}$ ) coincides with high observed $\mathrm{OH}$ concentrations $\left(\simeq 6 \times 10^{6} \mathrm{OH} \mathrm{cm} \mathrm{cm}^{-3}\right.$, June 25$)$, while during overcast days (June 23 and 24 ) only moderate levels, well below $1000 \mathrm{~cm}^{-3}$, were encountered.

\section{Conclusions}

Field measurements in the Black Forest yielded $\mathrm{OH}$ radical concentrations from below the detection limit up to $8.7 \times 10^{6} \mathrm{~cm}^{-3}$. Also pronounced diurnal profiles of the $\mathrm{OH}$ concentration could be observed, showing the $\mathrm{OH}$ concentration to be roughly, but not exactly, proportional to the photolysis frequency of ozone. Simultaneous to the $\mathrm{OH}$ measurements, a set of mixing ratios of other trace species, photolysis frequencies, and meteorologic parameters were measured. Because of technical reasons, those measurements integrated over volumes varying in spatial extension. However, existing evidence indicates that the air masses encountered during the measurement campaign were sufficiently homogeneous to extrapolate the in situ measurements to the air volumes along the $\mathrm{OH}$ and DOAS light paths. The data set presented in this publication constitutes a characterization of a single air mass sufficient for comparison of observed $\mathrm{OH}$ levels with reaction kinetic model calculations. Those model calculations, and the results of the comparison of modeled with measured $\mathrm{OH}$ levels, will be presented in a forthcoming publication.

Acknowledgments. The authors gratefully acknowledge the help of W. Weiss, H. Stockburger, and H. Sartorius, from the Bundesamt für Zivilschutz, as well as E. H. Schröter and W. Mattig from the Kiepenheuer Institute, for providing space for the laser light source and the spectrometers of the two optical experiments. The crew of the Feldberg weather station was very helpful in allowing us to set up our Xe-arc light source. We wish to thank T. Gebbard in allowing us to site a reflecting mirror at the Hochfahrn mountain We are particularly thankful to B. Schubert and S. Elliott for providing the HPLC formaldehyde data prior to publication, and to W. Weiss, and H. Sartorius for providing Rn data for the Freiburg and Schauinsland sites. The support of the work by a BMFT grant (KBF 52) is gratefully acknowledged.

\section{REFERENCES}

Bahe, F. C., U. Schurath, and K. H. Becker, The frequency of $\mathrm{NO}_{2}$ photolysis at ground level, as recorded by a continuous actinometer, Atmos. Environ., 14, 711-718, 1980.

Charlson, R. J., N. C. Ahlquist, H. Selvidge, and P. B. MacCready, Monitoring of atmospheric aerosol parameters with the integrating nephelometer, J. Air Pollut. Control Assoc., 19, 937-942, 1969.

Crutzen, P., A discussion of the chemistry of some minor constituents in the stratosphere and troposphere, Pure Appl. Geophys., 106-108, 1385-1399, 1973.

Fishman, J., and P. J. Crutzen, A numerical study of tropospheric photochemistry using a one-dimensional model, J. Geophys. Res., 82, 5897-5906, 1977.

German, K. R., Direct measurement of the radiative lifetime of the $A^{2} \Sigma^{+}\left(\nu^{\prime}=0\right)$ states of $\mathrm{OH}$ and $\mathrm{OD}, J$. Chem. Phys., 62, 2584-2587, 1975.

Goldman, A., and J. R. Gillis, Spectral line parameters for the $A^{2} \Sigma^{+}, \leftarrow X^{2} \Pi\left(\nu^{\prime}=0\right)$ band of $\mathrm{OH}$ for atmospheric and high temperatures, J. Quant. Spectrosc. Radiat. Transfer, 25, 111-135, 1981.
Harrison, A. W., Rayleigh volume scattering coefficients for freon12, freon-22, and sulfur hexafluoride, Can. J. Phys., 55, 1898-1901, 1977.

Hübler, G., D. Perner, U. Platt, A. Toennissen, and D. H. Ehhalt, Ground-level $\mathrm{OH}$ radical concentration: New measurements by optical absorption, J. Geophys. Res., 89, 1309-1319, 1984.

Kessler, C., Gasförmige salpetrige Säure $\left(\mathrm{HNO}_{2}\right)$ in der belasteten Atmosphäre, Ph.D thesis, Univ. of Cologne, Federal Republic of Germany, 1984.

Levy, H., Normal atmosphere: Large radical and formaldehyde concentrations predicted, Science, 173, 141-143, 1971.

Logan, J. A., M. J. Prather, S. C. Wofsy and M. B. McElroy, Tropospheric chemistry: A global perspective, J. Geophys. Res., 86, 7210-7254, 1981.

Lowe, D. C., U. Schmidt, and D. H. Ehhalt, A new technique for measuring tropospheric formaldehyde $\left[\mathrm{CH}_{2} \mathrm{O}\right]$, Geophys. Res. Lett., 7, 825-828, 1980.

Meier, R. R., and D. E. Anderson, Jr., Radiation field in the troposphere and stratosphere from $240-1000 \mathrm{~nm}$, I, General analysis, Planet Space Sci., 30, 923-933, 1982.

Perner, D., D. H. Ehhalt, H. W. Paetz, U. Platt, E. P. Roeth, and A. Volz, OH-radicals in the lower troposphere, Geophys. Res. Lett., 3, 466-468, 1976.

Perner, D., D. H. Ehhalt, H. W. Paetz, U. Platt, E. P. Roeth, and A. Volz, Comment on "Improved airborne measurements of $\mathrm{OH}$ in the atmosphere using the technique of laser-induced fluorescence"' by C. C. Wang, L. I. Davis, P. M. Selzer, and R. Munoz, J. Geophys. Res., 86, 12,155, 1981.

Perner, D., et al., Tropospheric OH concentrations: A comparison of field data with model predictions, J. Atmos. Chem., 5, 185-216, 1987.

Platt, U., and D. Perner, Direct measurements of atmospheric $\mathrm{CH}_{2} \mathrm{O}, \mathrm{HNO}_{2}, \mathrm{O}_{3}, \mathrm{NO}_{2}$, and $\mathrm{SO}_{2}$ by differential optical absorption in the near UV, J. Geophys. Res., 85, 7453-7458, 1980.

Platt, U., and D. Perner, Measurements of atmospheric trace gases by long path differential UV/visible absorption spectroscopy, in Optical and Laser Remote Sensing, edited by D. K. Killinger and A. Mooradian, Springer Ser. Opt. Sci., vol. 39, pp. 95-105, Springer, New York, 1983.

Platt, U., und D. Perner, Ein Instrument zur spektroskopischen Spurenstoffmessung in der Atmosphäre, Fresenius Z. Anal. Chem. 317, 309-313, 1984.

Rudolph, J., D. H. Ehhalt, A. Khedim, and C. Jebsen, Determination of $\mathrm{C}_{2}-\mathrm{C}_{5}$ hydrocarbons in the atmosphere at low parts per $10^{9}$ to high parts per $10^{12}$ levels, J. Chrom., 217, 301-310, 1981.

Schubert, B. Untersuchungen zum Nachweis und zur Chemie von Formaldehyd und Acetaldehyd in derunteren Troposphäre, Ph.D thesis, Univ. of Cologne, Federal Republic of Germany, 1988.

Tuazon, E. C., A. M. Winer, R. A. Graham, and J. N. Pitts, Atmospheric measurements of trace pollutants by kilometerpathlength FT-IR spectroscopy, Environ. Sci. Technol., 10, 259-299, 1980.

Twomey, S., Atmospheric aerosols, Elsevier Science, New York, 1977.

Weinstock, B., Carbon monoxide: Residence time in the atmosphere, Science, 166, 224-225, 1969.

Weiss, W., H. Stockburger, H. Sartorius, K. O. Münnich, M. Keller, T. Bühler, and U. Platt, Atmospheric aerosol and radioactivity parameters at the Schauinsland mountain top observatory, Proceedings of the WMO TECOMAC Conference, Vienna, Oct. 17-21, 1985, WMO 647, pp. 361-373, 1985.

D. H. Ehhalt, U. Platt, and J. Rudolph, Institut 3, Atmosphärishe Chemie, Institut für Chemie der Kernforschungsanlage Jülich GmbH, Postfach 1913, 5170 Jülich, Federal Republic of Germany. W. Junkermann, Fraunhofer Institut für Atmosphảrishe Umweltforschung, Kreuzeckbahnstrasse, D-8100 Garmisch-Partenkirchen, Federal Republic of Germany.

M. Rateike, Bayer Aktiengesellschaft, D-5090 Leverkusen, Federal Republic of Germany.

(Received July 22, 1987; revised January 15, 1988; accepted January 18, 1988.) 